International Journal of Nano Studies \& Technology (IJNST) ISSN 2167-8685

\title{
Development and Evaluation of an Aqueous Polymeric Dispersion of Eudragit L 100-55 Using Emulsification Technology
}

Research Article

Singh $\mathrm{S}^{1}$, Mittal A ${ }^{1}$, Gupta $\mathrm{N}^{1}$, Chauhan $\mathrm{N}^{1}$, Alam S ${ }^{1^{*}}$

${ }^{1}$ Department of Pharmaceutics, KIET School of Pharmacy, Ghaziabad, U.P, India.

\section{Abstract}

Aqueous polymer dispersions (APD) are preferred on environmental and safety grounds. APD offer several advantages over polymers dissolved in organic solvents including lower spraying viscosities, higher solids loading, higher spray rates, no solvent environmental, toxicity, or flammability issues, and reduced energy requirements. The purpose of this work is to prepare and characterize an aqueous-based pseudolatex dispersion of Eudragit L100-55 using emulsification technology with superior stability. The prepared APD is evaluated on the basis of organoleptic, physical, chemical and in-vitro drug release performance. APD film is prepared by casting method and evaluated. Coating is done over Diclofenac sodium tablet and In vitro drug release profile of APD coated tablet and organic coated tablet is studied and shows better release in case of APD as compared to market formulation and organic coating.

Key Words: Aqueous Polymeric Dispersion (APD); Emulsification Solvent Evaporation; Latex; Pseudolatex; TEM; DSC.

\section{*Corresponding Author:}

Sanjar Alam

Department of Pharmaceutics, KIET School of Pharmacy, Ghaziabad, U.P, India.

Tel: +91- 9891674226

E-mail: sanjaralam10@gmail.com

Received:November 07,2013

Accepted: November 21, 2013

Published: November 22, 2013

Citation: Alam S, et al. (2013). Development and Evaluation of an Aqueous Polymeric Dispersion of Eudragit L 100-55 Using Emulsification Technology, Int J Nano Stud Technol, 02(05), 33-39. doi: http:// dx.doi.org/10.19070/2167-8685-130007

Copyright: Alam S $\mathbf{S}^{\mathscr{O}}$ 2013.This is an open-access article distributed under the terms of the Creative Commons Attribution License, which permits unrestricted use, distribution and reproduction in any medium, provided the original author and source are credited.

\section{Introduction}

Coating with water insoluble polymers is an important technique for targeted or controlled release formulations and the tastemasking of drugs, during which the aqueous polymer dispersions are widely used as an alternative to an organic polymer coating system [1] .Water soluble polymers are always being in good demand because of their certain advantages over organic solvents with respect to ecological, toxicological and manufacturing safety concern, high cost of organic solvents, solvent toxicity [2]

Aqueous polymeric dispersions, latexes, or pseudo latexes are all colloidal systems in which high molecular weight polymers are homogeneously dispersed in submicron sizes with the aid of surfactant(s) and other stabilizing agents. aqueous dispersion containing hydrophobic material that are useful as reduced volatile content may be used as a coating, resin, or an additive [3]

\section{Types of aqueous polymeric dispersion}

Aqueous polymeric dispersions that are widely used by the pharmaceutical industry are manufactured using different processes and different starting materials. They are classified into:

- Latex

Latexes are aqueous polymeric dispersions produced by emulsion polymerization. The homogeneous and heterogeneous nucleation models have been proposed to describe such processes. As a direct outcome of the manufacturing process, latex may contain not only polymers, but also surfactants, as well as traces of initiators and monomers that must be eliminated as completely as possible from the lattice used in pharmaceutical applications $[4,19,20]$.

\section{- Pseudo latexes}

Pseudo latexes are prepared by dispersion of the bulk polymer in an aqueous medium. The pseudolatex dispersion, a coating formulation often includes plasticizers to enhance the flexibility of the film and facilitate polymer sphere coalescence, antiadherents to prevent substrate agglomeration during both the coating process and storage, surfactants to promote spreading of the atomized droplets own the substrate surface, and pigments. The addition of other excipients can significantly impact the physical stability of the dispersion, drug release, and film quality $[5,19,20]$. An APD can be prepared in two different forms:

a. Ready to use: milky white liquid

b. Freeze dried / spray dried: powdered

\section{Different techniques used in APD}

Water insoluble polymers can be converted into aqueous dispersions by emulsion polymerization, emulsion solvent evaporation, phase inversion, or solvent change method. 
- Emulsification technique

Emulsification polymerization

D Direct Emulsification/ emulsion solvent evaporation

$»$ Self Emulsification

》 Phase Inversion Emulsification or Solvent change method

1. Nanotechnology

2. $\mathrm{pH}$ modification

3. Phase separation/ coacervation

\section{Materials and Methods}

\section{Materials}

Eudragit L100-55 was received as a gift sample from Evonik industries, Mumbai. Diclofenac sodium was purchased from Omega pharmaceuticals, India and Poloxamer 407 \& Sodium lauryl sulphate (SLS) were supplied by Central Drug House (P) Ltd., Mumbai. All other chemicals were of either reagent or analytical grade as received.

Table 1: Different types of emulsification

\begin{tabular}{|c|c|c|c|}
\hline Properties & Direct & Inversion & Self \\
\hline Definition & $\begin{array}{l}\text { The liquid polymer in a } \\
\text { volatile organic solvent } \\
\text { is emulsified in water } \\
\text { that contain emulsifier } \\
\& \text { stabilizer by using } \\
\text { conventional emulsifi- } \\
\text { cation method [7] }\end{array}$ & $\begin{array}{l}\text { The liquid polymer in an organic solvent is compound- } \\
\text { ed with long fatty acid with conventional rubber mix- } \\
\text { ing equipment. Water in polymer inverts to polymer in } \\
\text { water emulsion. } \\
\text { Phase inversion is complete, which means that all water } \\
\text { molecules in the system are transformed to be continu- } \\
\text { ous phase at the phase inversion point [8] }\end{array}$ & $\begin{array}{l}\text { Polymer molecules are } \\
\text { modified chemically } \\
\text { by the introduction of } \\
\text { basin or acidic group } \\
\text { \&self emulsification } \\
\text { occurs [6] }\end{array}$ \\
\hline Droplet size & $1 \mu \mathrm{m}$ or larger & $0.8-1 \mu \mathrm{m}$ or larger & Small as $0.1 \mu \mathrm{m}$ \\
\hline Ease of preparation & Easy to prepare & Require great care and control & Not easy to prepare \\
\hline Cost & Economic & Expensive & Expensive \\
\hline Example & Eudragit & Polyacrylamide \& its co- polymer [9] & \\
\hline
\end{tabular}

Table 2: Formulation of different concentration of APD

\begin{tabular}{|l|l|l|l|l|l|l|l|l|l|l|l|l|}
\hline Ingredients & Example & F1 & F2 & F3 & F4 & F5 & F6 & F7 & F8 & F9 & F10 & F 11 \\
\hline Polymer(g) & Eudragit L 100-55 & 0.5 & 1 & 1.5 & 2 & 2.5 & 3 & 3.5 & 4.0 & 4.5 & 5 & 6 \\
\hline Organic solvent(ml) & Acetone & 20 & 20 & 20 & 20 & 30 & 30 & 30 & 30 & 30 & 30 & 30 \\
\hline Stabilizer(\%w/w) & Poloxamer 407 & 6 & 6 & 6 & 6 & 6 & 6 & 6 & 6 & 6 & 6 & 6 \\
\hline Surfactant(\%w/v) & SLS & 1 & 1 & 1 & 1 & 2 & 2 & 2 & 2 & 2 & 2 & 2 \\
\hline Aqueous phase(m) & Distilled water & 50 & 50 & 50 & 50 & 50 & 50 & 50 & 50 & 50 & 50 & 50 \\
\hline
\end{tabular}

\section{Development of an APD}

Several formulations were developed using the emulsification methodology. Solvents for the organic phase was acetone, SLS was taken as surfactant and poloxamer 407 as stabilizer $[10,15,16,17,18]$.

The Eudragit L100-55 dispersion was prepared by emulsion solvent evaporation method. Accurately weighed Eudragit L100-55 was dissolved in acetone, and the resulting solution was dispersed in $50 \mathrm{ml}$ of aqueous phase having surfactant and stabilizer, at room temperature using a Mechanical stirrer (Hicon Instrument Manufacture Co. Ltd. India). The type of the emulsion was determined by diluting the emulsions with either water or acetone. Then the emulsion was subjected to rota evaporator (Perfit, India).To optimize the formulation various batches were made which is given in Table 2 .

\section{Pseudolatex (APD) characterization}

» Organoleptic characterization: On the basis of color, odour and appearance APD was characterized[11]

»Viscosity: Viscosity was measured with a Brookfield DV III Ultra programmable rheometer at $20^{\circ} \mathrm{C}, 30 \mathrm{rpm}[11,12,13]$.

» Differential scanning Calorimeter (DSC): DSC study is done for the authentication of the drug[14].

» Particle size distribution: It is measured by zeta sizer instrument Malvern Instrument outsourced from Jamia Hamdard[14].

» Scanning electron microscopy: Scanning electron microscopy has been used to determine the surface morphology and texture. SEM studies were carried out by using Zeiss scanning microscope[16,17]. 
$»$ Transmission electron microscopy: Transmission electron microscopy has been used to determine the surface morphology and texture[18,19].

Z Zeta Potential: Zeta potential is measured by zeta potential analyzer outsourced from Jamia Hamdard[14,20].

» Solid content (wt\%): The solid content of the dispersion was measured as follows: an accurately weighed amount of the dispersion (about $1 \mathrm{~g}$ ) was spread on a disc and dried for at least $3 \mathrm{~h}$ at $110^{\circ} \mathrm{C}$ to constant weight (according to $\mathrm{Ph}$. Eur. 2.2.32d). The solid content ( $w \mathrm{t} \%$ ) was the ratio of the dried residue weight to the original weight of the disper$\operatorname{sion}[21,22]$.

$$
\% \text { solid Content }=\frac{\begin{array}{c}
\text { \%solid Content }((\text { Weight of } \\
\text { dish }+ \text { residue })- \text { Weight of dish })
\end{array}}{\text { (Weight of sample })} \times 100
$$

\section{- In vitro drug release}

The dissolution test for APD coated tablets was performed according to USP (USP 2007) adopting method B in pH 1.2 and $\mathrm{pH} 6.8$ buffers. Drug release was measured in a USP dissolution bath using apparatus II at $50 \mathrm{rpm}$. In the first stage ( $\mathrm{pH} \mathrm{1.2);} \mathrm{the}$ tablets were putted in $900 \mathrm{ml}$ of $0.1 \mathrm{~N}$ hydrochloric acid in a USP dissolution bath equilibrated to a temperature of $37 \pm 0.5^{\circ} \mathrm{C}$. The paddle stirring rate was set at $50 \mathrm{rpm}$. Six tablets were introduced into the apparatus and the apparatus was run for $2 \mathrm{~h}$. After the operation outlined above, an aliquot of the fluid was drawn, and the second stage ( $\mathrm{pH}$ 6.8) was commenced. This last consisted of a phosphate buffer of $\mathrm{pH} 6.8$ prepared by mixing $0.1 \mathrm{M}$ hydrochloric acid with $0.20 \mathrm{M}$ tribasic sodium phosphate (3:1). The apparatus was operated for a further 45 minutes. At the end of the time period, an aliquot of the fluid was drawn. Samples were as sayed by UV method, at $273.4 \mathrm{~nm}$ wave length [23,24].

The following characteristics were determined for a dispersion obtained with a good yield, i.e. which formula could be used for an industrial scale-up. The $\mathrm{pH}$ was determined by using a $\mathrm{pH}$ meter.

\section{Evaluation of APD film}

For the development of APD film 10\% concentration of TEC was optimized as plasticizer. APD film was evaluated on the basis of physical parameters e.g., weight, thickness, folding endurance, percentage moisture uptake and percentage moisture content.

\section{- Physical appearance}

The films were observed visually for their completeness, uniformity, surface texture and flexibility.

\section{- Moisture Content}

The prepared films were marked, then weighed using shimadzu (AU x 220) digital balance individually and kept in a desiccators containing activated silica at room temperature for $24 \mathrm{~h}$. The films were weighed again and again individually until it showed a con stant weight. The percentage moisture content was calculated as a difference between initial and final weight with respect to final weight

- Percentage Moisture Uptake

A weighed film kept in desiccators at normal room temperature for 24 hours was taken out and exposed to $84 \%$ relative humidity (saturated solution of potassium chloride) in desiccators until a constant weight for the film was obtained. The percentage of moisture uptake was calculated as the difference between final and initial weight with respect to initial weight (Arora et al., 2002).

\section{- Thickness}

The thickness of the film was measured at three different points using a micrometer screw gauge and average thickness recorded.

\section{- Folding Endurance}

Folding endurance was determined by repeatedly folding the film at the same place until it broke. The number of times the film could be folded at the same place without breaking was the folding endurance value.

\section{Result and Discussion}

\section{DSC of drug}

DSC study shows the melting point of the dug at $284.9^{\circ} \mathrm{C}$ which is corroborated with the literature value.

\section{FTIR study}

The FT-IR of the drug is shown in fig 2 whereas the APD coating is shown in fig 3. which shows that the drug is coated with APD

\section{HPLC method for diclofenac sodium}

a. Equipment: Shimadzu HPLC with an attached UV detector.

b. Column: C18 reversed- phase column $(25 \mathrm{~cm} \times 4.6 \mathrm{~mm}$, particle size $5 \mu \mathrm{m})$

c. Mobile phase: Acetonitrile: water (60:40)

d. Flow rate: $1 \mathrm{ml} / \mathrm{min}$.

e. Detection: UV, $273.4 \mathrm{~nm}$

f. Injection: $20 \mu \mathrm{l}$

The calibration curve of Diclofenac was prepared by HPLC method for the determination of drug content and in vitro analysis. The HPLC chromatogram of drug is shown in fig. 4

\section{APD Development}

During preliminary studies, several surfactants were studied as stabilizers for the preparation of the pseudolatexes. Using cetyl alcohol as the stabilizer, the produced pseudolatexes were converted into gel-like substances within one hour. A stable dispersion was obtained with poloxamer 407 (Pluronic F 127) given in table 3 . 
Figure 1: DSC of drug (Diclofenac sodium)

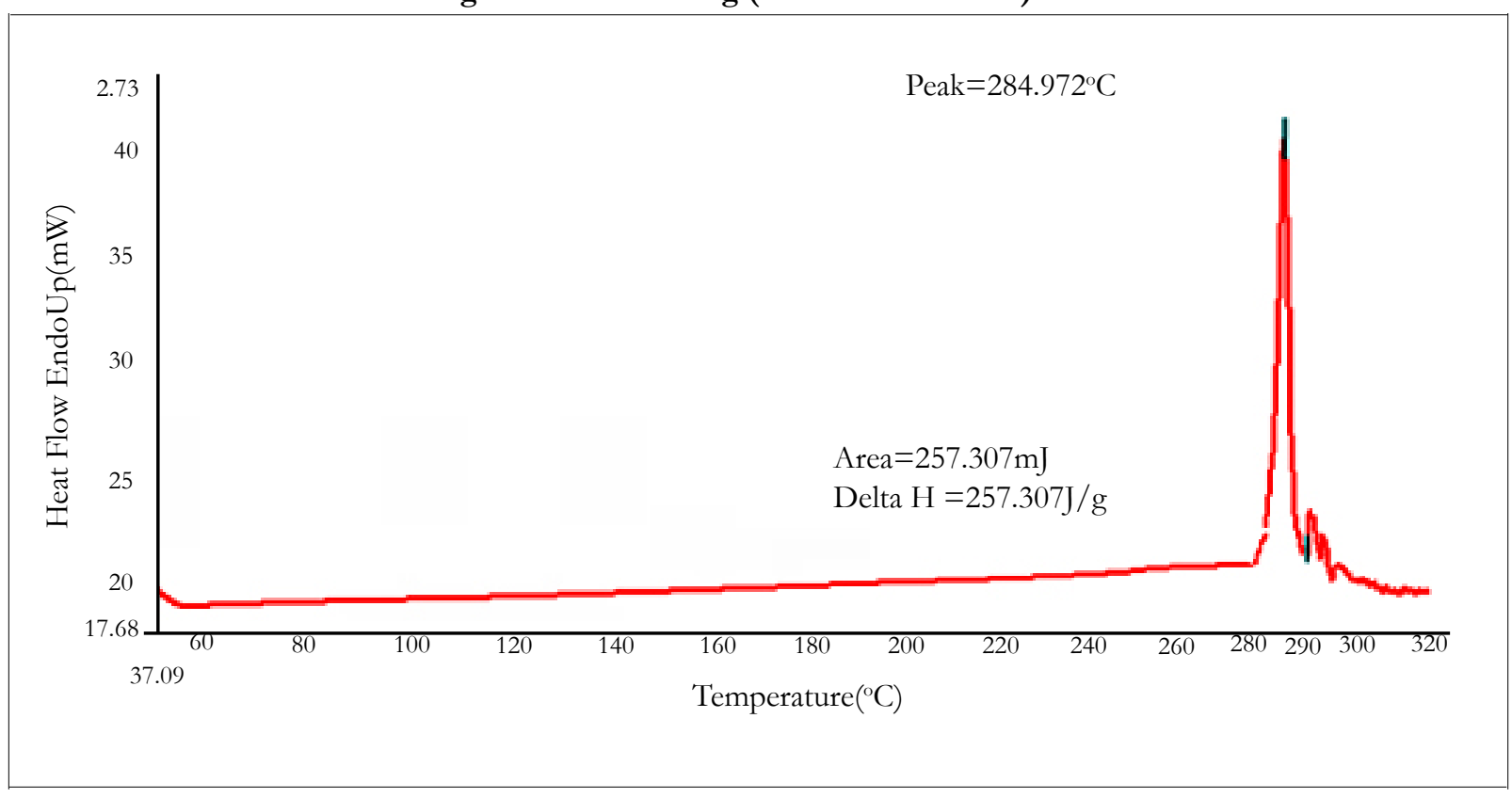

Figure 2: FT-IR spectrum of Diclofenac sodium

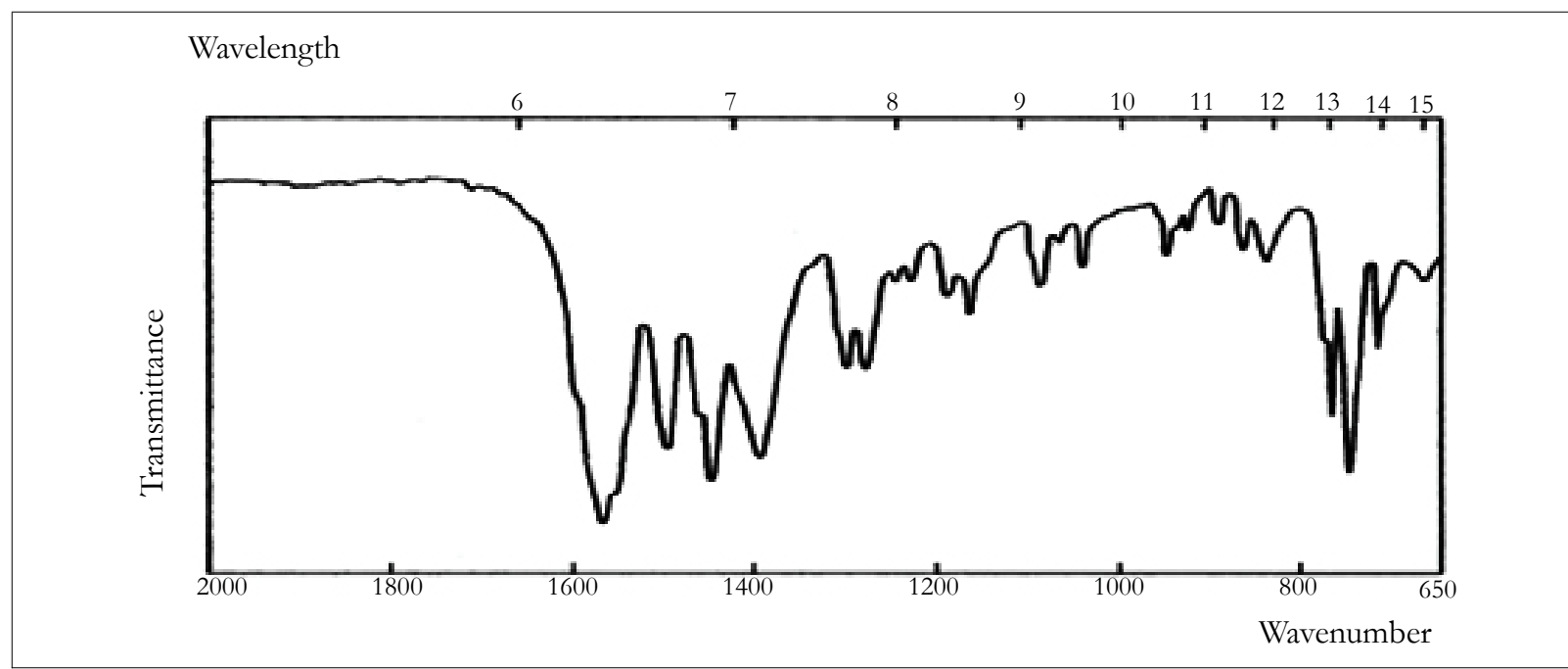

Figure 3: FT-IR spectrum of APD coating

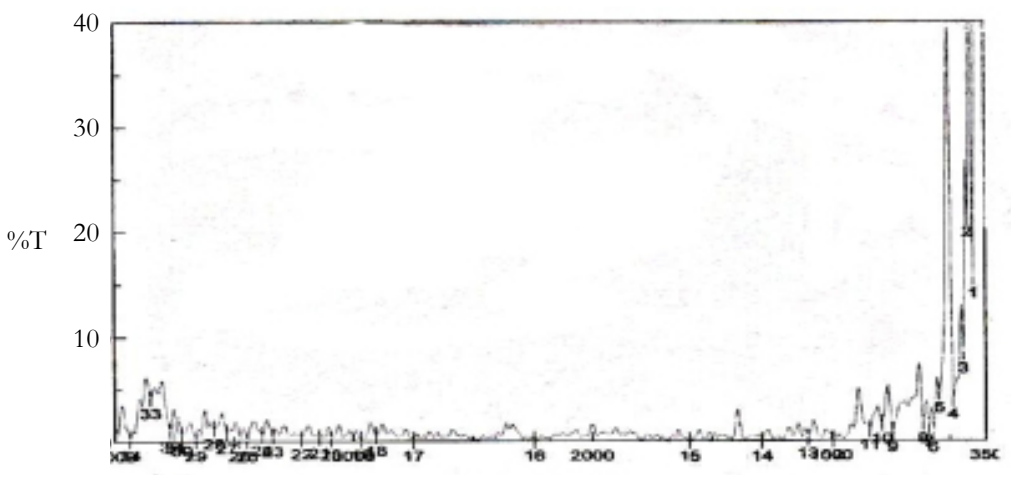

Wavenumber $\mathrm{cm}-1$ 
Figure 4: HPLC chromatogram of Diclofenac sodium in mobile phase

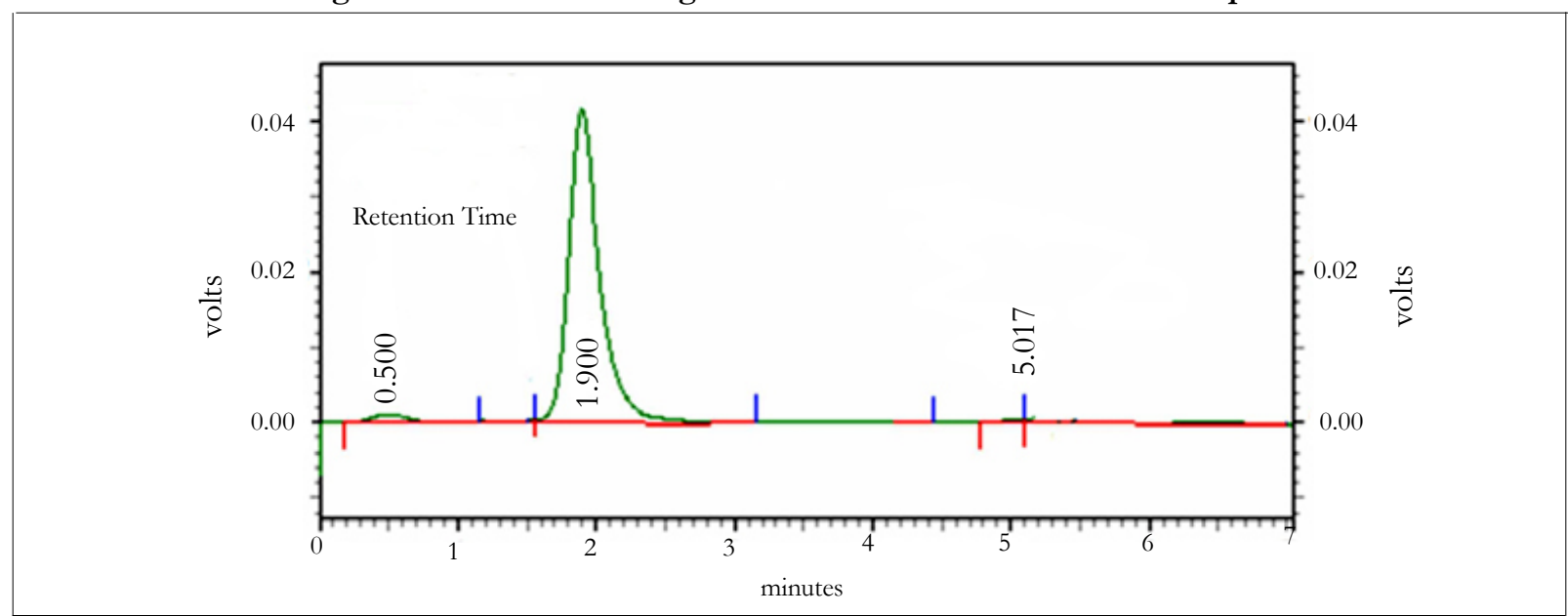

Table 3: Formula for 10\%APD (F10)

\begin{tabular}{|l|l|l|}
\hline \multicolumn{3}{|c|}{ For 10\% APD } \\
\hline Ingredients & Example & Quantity \\
\hline Polymer & Eudragit L 100-55 & $5 \mathrm{~g}$ \\
\hline Organic solvent & Acetone & $30 \mathrm{ml}$ \\
\hline Stabilizer & Poloxamer 407 & $6 \% \mathrm{w} / \mathrm{w}$ \\
\hline Surfactant & Sodium lauryl sulphate & $2 \% \mathrm{w} / \mathrm{v}$ \\
\hline Aqueous phase & Distilled water & $50 \mathrm{ml}$ \\
\hline
\end{tabular}

\section{Characterization of APD}

- Transmission Electron Microscopy(TEM)

TEM image shows the spherecity of the APD developed and the smoothness of the surface texture as shown in fig 5 .

- $\quad$ Particle Size and Zeta Potential

The stability of the dispersions was found to be dependent on the amount of poloxamer 407 ( $\mathrm{wt} \%$ of the polymer). The particle size decreased significantly on increasing the amount of Poloxamer 407, while no significant changes were observed above $6 \%$. Increasing the amount of poloxamer 407 produced little change in the zeta potential. The final optimized dispersion (solid content percentage about $15.9 \%$ ) was obtained with an average particle size of $611 \mathrm{~nm}$ given in fig 6 (A), and a $\mathrm{pH}$ of 3.50 A zeta potential of $-30.3 \mathrm{mV}$ was measured given in fig $6(\mathrm{~B})$.

\section{Evaluation of film}

The physical evaluation of the developed APD such as thick-

Figure 5: TEM photograph of $10 \%$ emulsion

Figure 6: (A) Zeta potential

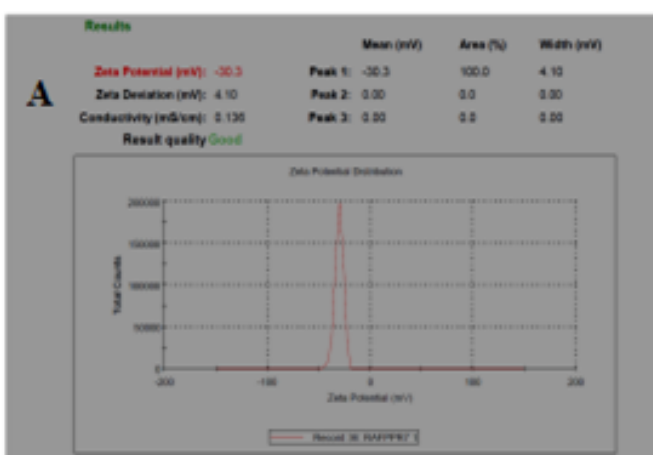

Figure 6: (B) Particle size of $10 \%$ aqueous polymeric dispersion

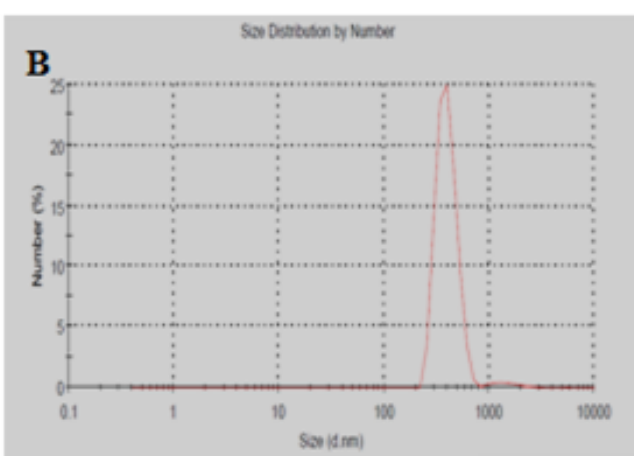


Figure 7: Comparative \% release profile for different concentration of APD

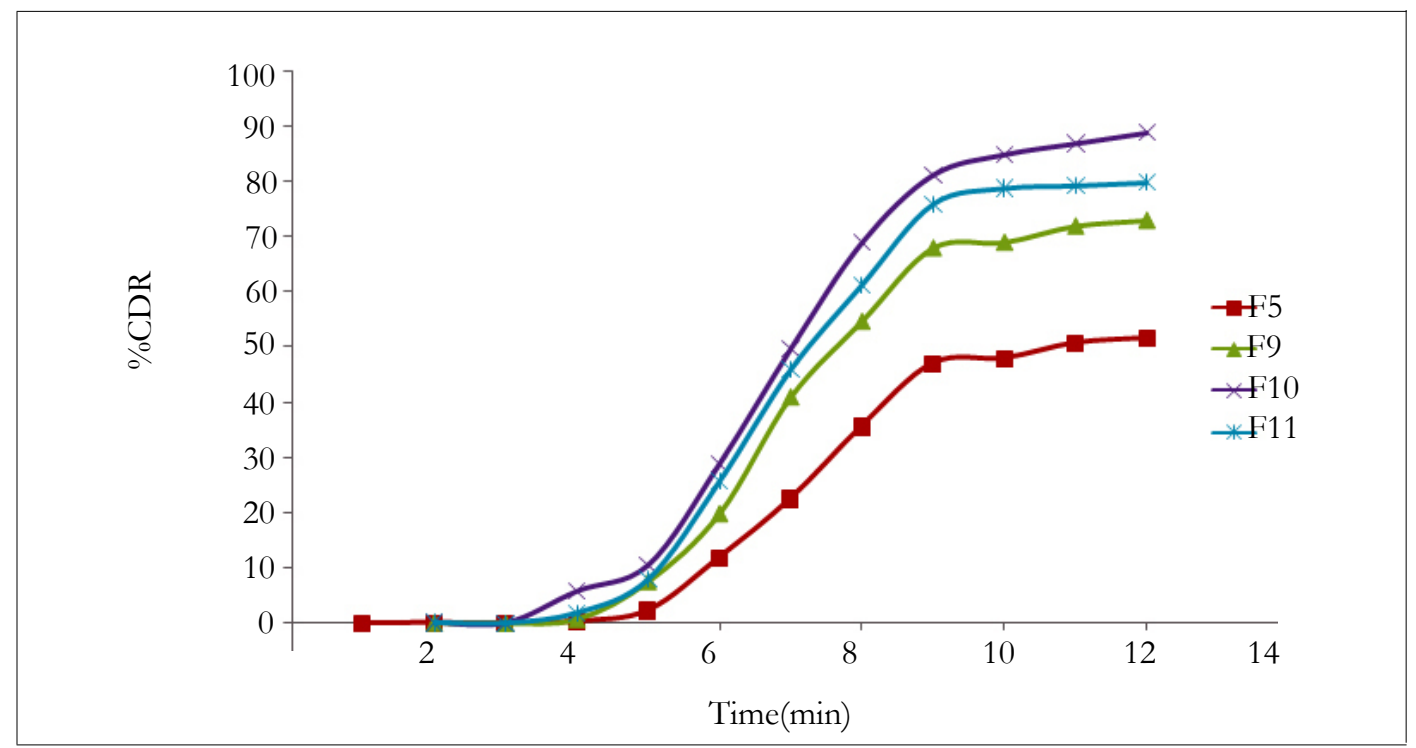

Figure 8: Comparative drug release profile

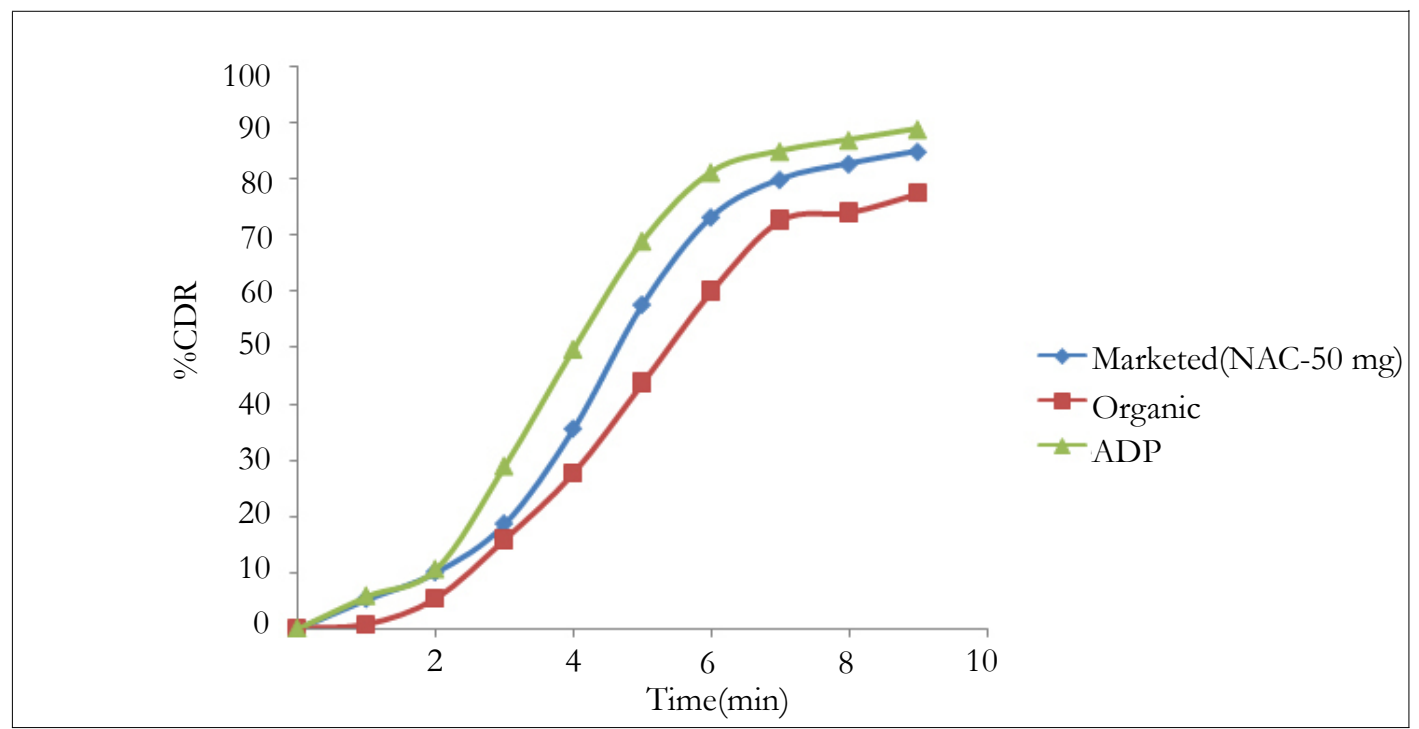

Table 4: Physical Parameters of APD film

\begin{tabular}{|l|l|l|l|l|l|}
\hline S.No. & Weight $(\mathbf{m g})$ & Thickness $(\boldsymbol{\mu})$ & Folding endurance & \% moisture uptake & Moisture content \\
\hline $\mathbf{1}$ & 22.4 & 131 & 230 & 15.90 & 4.00 \\
\hline
\end{tabular}

Table 5: Model fitting of the drug release profile

\begin{tabular}{|l|l|l|l|l|}
\hline Formulation & Zero Order Equation R2 & First Order Equation R2 & Higuchi Equation R2 & Korsmeyer Peppas Model R2 \\
\hline F10 & 0.936 & 0.958 & 0.877 & 0.951 \\
\hline
\end{tabular}

Table 6: Stability study of APD

\begin{tabular}{|l|l|l|l|l|}
\hline S. No. & Time in month & $\mathbf{p H}$ & Viscosity & Appearance \\
\hline $\mathbf{1}$ & 1 & 3.60 & 8.0 & No agglomeration \\
\hline $\mathbf{2}$ & 2 & 3.60 & 8.0 & No agglomeration \\
\hline $\mathbf{3}$ & 3 & 3.71 & 8.2 & No agglomeration \\
\hline
\end{tabular}

ness, moisture content, moisture uptake as well as folding endurance is given in table 4 .

\section{Drug release}

The drug release profile of the different APD is given in fig 7 whereas comparative release profile of the optimized APD with respect to the marketed as well as organic based polymeric dispersion is given in fig 8 .

\section{Drug release kinetics}

Model fitting of drug release profile is shown in table 5. The high $\mathrm{R} 2$ value is near to unity and is maximum that is 0.958 in case of first order for optimized APD. So its follows the first order kinetics. The slope(n) in case of korsmeyer peppas model was 
found to be more than 0.5 which further suggest non- fickian diffusion method.

\section{Stability studies}

The optimal formulation was evaluated for stability studies by storing at 40 degree Celsius at $75 \%$ RH \& tested for 3 months. The APD was analyzed for physical parameters given in table 6 . The dispersion was stable and no sedimentation occurred after 3 month storage

\section{Conclusion}

APD of Eudragit L100-55 was prepared by the emulsification technology (emulsion solvent evaporation method) using Poloxamer 407 as the stabilizer and SLS as a surfactant. A stable dispersion was obtained through the optimization of surfactant and stabilizer. The optimized concentration of stabilizer and surfactant was $6 \% \mathrm{w} / \mathrm{w}$ of polymer and $2 \% \mathrm{w} / \mathrm{v}$, respectively for Eudragit L-100-55 dispersion. Different concentration of APD was prepared and evaluated.

On the basis of Organoleptic properties, chemical characterization and in vitro drug release performance formulation F10 $(10 \%$ APD) was found to be better than the other formulations. Organoleptic and chemical characterization included appearance, odour, $\mathrm{pH}$, viscosity, particle size-shape, zeta potential and $\%$ solid content. Appearance of 10\% APD was milky white and $\mathrm{pH}$ was 3.5. Viscosity was $8.0 \mathrm{mPa}$.s measured by Brookfield rheometer using 3no.spindle, $30 \mathrm{rpm}$. Particle surface morphology was done by SEM analysis. Particle size was measured by zeta sizer and was found to be $611 \mathrm{~nm}$. Zeta potential of the optimized APD was $-30.3 \mathrm{mV}$.The present dispersion exhibited superior stability with regard to temperature and $\mathrm{pH}$ changes. The evaluation parameters of the free film were well controlled by the plasticizer concentration.

Formulation of uncoated tablet of Diclofenac sodium was done by wet granulation method. Enteric coating was successfully done using $10 \%$ aqueous dispersion of Eudragit L 100-55. In vitro drug release of $10 \%$ APD was $88.95 \%$. In vitro drug release of APD coated tablet was higher than organic coated tablet. FTIR and UV studies did not show any evidence of interaction between the drug and the polymers. The preparation of this aqueous dispersion is easy and requires short time which decreases the cost of the coating process. The results of the present study suggest that the aqueous-based dispersion of acrylic polymers can be used in a wider variety of conditions for coating.

\section{Acknowledgement}

Authors are thankful to the principal KIET school of Pharmacy Ghaziabad for providing the best research facilities available for conducting the research work. Authors are also thankful for the support provided by Advanced Instrumentation Research Facility (AIRF), Jawaharlal Nehru University and Nano Medicine lab, Faculty of Pharmacy, Jamia Hamdard, New Delhi.

\section{References}

[1]. Xinke Caoa, C, Qizhen Gaob, Ping Gaoa, Pingtian Dinga, , Zibin Gaoa, Xiyang Suna. Preparation And Characterization Of A Novel Aqueous Dispersion Of Eudragit E For Coating Dispersions Of Eudragit E For Coating, Asian Journal Of Pharmaceutical Sciences.2007;2: 29-37

[2]. Pawar Avinash S., Bageshwar Deepak V., Khanvilkar Vineeta V., Kadam Vilasrao J. Advances In Pharmaceutical Coatings, International Journal Of Chemtech Research. 2010;2: 733-737

[3]. Jones David.Pharmaceutical Application Of Polymers For Drug Delivery.2004;15:3-5

[4]. Raizada Ankita, Bandari Anil, Kumar Brijesh. Polymers In Drug Delivery: A Review, International Journal Of Pharma. Research And Development.2002;2:9-20

[5]. Ronald Obei.Aqueous Dispersion Utilizing Corboxyalkyl Cellulose Esters And Water Reducible Polymers, United State Patent

[6]. Mehta Naveen, Gupta Mahesh Kumar, Jain Anurekha. Aqueous Polymeric Dispersion(APD) a Third Generation (3G) Pharmaceutical Coating System,Inventi Journal.2011:103-106

[7]. Ms Mittal N Zala .Techniques For Powder Particle Coating: A Review ,International Journal Of Pharma World Research, 2011;2:1-5

[8]. Yang Zhenzhong, Xu Yuanze, Zhao Delu. Preparation Of Water Based Dispersions Of Epoxy Resin By Phase Inversion Emulsification Technique Study On Rheological Behavior Of Phase Inversion.1998

[9]. Vanderhoff J.W. Inversion Emulsion Polymerization of Acrylamide: Polymerization Kinetics and Process Development, Journal Of Dispersion Science And Technology. 1984;5:323-363

[10]. Hua Zou, Shishan Wu, and Jian Shen. Polymer/Silica Nanocomposites: Preparation, Characterization, Properties, and Applications, Chem. Rev. 2008;108: 3893-3957

[11]. Valter Castelvetro, Cinzia De Vita, Nanostructured Hybrid Materials From Aqueous Polymer Dispersions. Advances in Colloid And Interface Science. 2004:167-185

[12]. Percy M. J. et.al. , Synthesis of Vinyl Polymer-Silica Colloidal Nanocomposites Via Aqueous Dispersion Polymerization. 2003;19:, 2072-2079

[13]. Allémann E. Preparation of Aqueous polymeric Nanodispersions By A Reversible Salting-Out Process: Influence Of Process Parameters On Particle Size, International Journal Of Pharmaceutics. 1992;87: 247-253

[14]. Hideki Murakami, Masao Kobayashi, Hirofumi Takeuchi, Yoshiaki Kawashima. Preparation Of Poly(Dl-Lactide-Co-Glycolide) Nanoparticles By Modified Spontaneous Emulsification Solvent Diffusion Method,International Journal Of Pharmaceutics .1999;187: 143-152

[15]. James W Macginity, Linda A. Felton,Aqueous Polymeric Coatings For Pharmaceutical Dosage Forms, Third Edition.176:1-47

[16]. Takashi Takayanagis, Masaaki Yamabe, Progress of fluoropolymers on coating applications Development of mineral spirit soluble polymer and aqueous dispersion Progress in Organic Coatings .2000;40:185-190

[17]. Bodmeier R., Paeratakul, O.,Dry and wet strength of polymeric films prepared from an aqueous colloidal polymer dispersion, Eudragit RS30D. Int J Pharm.1993; 96: 129-138.

[18]. Brown GL., Formation of films from polymer dispersions, J Polym Sci.1966; 22(102): 423-434.

[19]. Chevalier Y et al., Film formation with latex particles. Colloid Polym Sci. 1992; 270 (8): 806-821.

[20]. Dillon RE, Matheson LA, Bradford EB.,Sintering of synthetic latex particles. J Colloid Sci.1951; 6(2):108-117.

[21]. F. T. Hesselink, A. Vriz., On the theory of the stabilization of dispersion by adsorbed macromolecules II. Interaction between two paticles. J. Phys. Chem. 1971; 75: 2094-2103.

[22]. H. P. Nilesh, C. P. Stuart., Tensile properties of free film cast from aqueous ethylcellulose dispersions. Pharm. Res.1993; 10: 810-815.

[23]. Hahn K, Ley G, Oberthür R.., on particle coalescence in latex films (II). J Colloid Polym Sci .1988; 266(7): 631-639.

[24]. Valter Castelvetro,Cinzia De Vita.,Nanostructured Hybrid Materials From Aqueous Polymer Dispersions. Advances In Colloid And Interface Science. 2004; 108(109)167-185. 